\title{
Slope spectrum critical area and its spatial variation in the Loess Plateau of China
}

\author{
TANG Guoan ${ }^{1,2,3}$, SONG Xiaodong ${ }^{4}$, LI Fayuan ${ }^{1,2,3}$, ZHANG Yong ${ }^{5}$, XIONG \\ Liyang ${ }^{1,2,3}$
}

1. Key Laboratory of Virtual Geographic Environment (Nanjing Normal University), Ministry of Education, Nanjing 210023, China;2. State Key Laboratory Cultivation Base of Geographical Environment Evolution (Jiangsu Province), Nanjing 210023, China;3. Jiangsu Center for Collaborative Innovation in Geographical Information Resource Development and Application, Nanjing 210023, China;4. State Key Laboratory of Soil and Sustainable Agriculture, Institute of Soil Science, CAS, Nanjing 210008, China;5. Key Laboratory of Radiometric Calibration and Validation for Environmental Satellites, National Satellite Meteorological Center, China Meteorological Administration, Beijing 100081, China

Abstract: Slope spectrum has been proved to be a significant methodology in revealing geomorphological features in the study of Chinese loess terrain. The determination of critical areas in deriving slope spectra is an indispensable task. Along with the increase in the size of the study area, the derived spectra are becoming more and more alike, such that their differences can be ignored in favor of a standard. Subsequently, the test size is defined as the Slope Spectrum Critical Area (SSCA). SSCA is not only the foundation of the slope spectrum calculation but also, to some extent, a reflection of geomorphological development of loess relief. High resolution DEMs are important in extracting the slope spectrum. A set of 48 DEMs with different landform areas of the Loess Plateau in northern Shaanxi province was selected for the experiment. The spatial distribution of SSCA is investigated with a geo-statistical analysis method, resulting in values ranging from $6.18 \mathrm{~km}^{2}$ to $35.1 \mathrm{~km}^{2}$. Primary experimental results show that the spatial distribution of SSCA is correlated with the spatial distribution of the soil erosion intensity, to a certain extent reflecting the terrain complexity. The critical area of the slope spectrum presents a spatial variation trend of weak-strong-weak from north to south. Four terrain parameters, gully density, slope skewness, terrain driving force $\left(T_{d}\right)$ and slope of slope (SOS), were chosen as indicators. There exists a good exponential function relationship between SSCA and gully density, terrain driving force $\left(T_{d}\right)$ and SOS and a logarithmic function relationship between SSCA and slope skewness. Slope skewness increases, and gully density, terrain driving force and SOS decrease with increasing SSCA. SSCA can be utilized as a discriminating factor to identify loess landforms, in that spatial distributions of SSCA and the evolution of loess landforms are correlative. Following the evolution of a loess landform from tableland to gully-hilly region, this also proves that SSCA can represent the development degree of local landforms. The critical stable regions of the Loess Plateau represent the degree of development of loess landforms. Its chief significance is that the perception of stable areas can be used to determine the minimal geographical unit.

Keywords: digital elevation model; slope spectrum; critical area; spatial variation; independent geomorphological unit; Loess Plateau

J. Geogr. Sci. 2015, 25(12): 1452-1466

DOI: $10.1007 /$ s11442-015-1245-0

\section{Introduction}


The Loess Plateau of China has attracted much attention in the field of geoscience due to its specific loess landforms as well as for having the most severe soil erosion in the world (Shi et al., 2000; Hessel et al., 2003). A great deal of research has arisen since the 1950s from attempts to interpret various aspects of the landforms, such as the geological structure (Liang et al., 2004), soil and water conservation (Jing, 1986; He et al., 2003; Chen et al., 2007) and the geomorphological characteristics (McBride et al., 2007; Yang et al., 2011; Xiong et al., 2014a, 2014b), but has ignored the basic methodology for establishing a quantitative landform evolution model of the Loess Plateau (Rowbotham, 1998; Hughes et al., 2010). However, it is a crucial problem in correctly explaining the classification and topographic regions of the Loess Plateau (Luo, 1956). From a qualitative and quantitative research perspective, Luo (1956) analyzed and divided the loess landform into morphological and genetic types. Zhou et al. (2011) studied the characteristics of landform combinations and their regional distribution using proposed quantitative research methods. Recently, more attentions have been paid to geomorphological surveying by means of land surface parameters in digital elevation models (DEMs) (Iwahashi et al., 2001; Xu et al., 2009; Matsushi et al., 2010; Cheng et al., 2014; Tong et al., 2014).

It is widely accepted that slope is a primary land surface parameter that affects the formation and intensity of soil erosion in areas with serried gullies and fragmented landforms (Yamada, 1999; Shi et al., 2000; Hessel et al., 2003; Ayalew et al., 2004). Slope can be calculated from DEMs without further knowledge of the represented area (Shary et al., 2002; Tang et al., 2003; Zhou et al., 2006a). It is an interesting discovery that different loess landforms possess a stable frequency distribution histogram, which could be used as an effective indicator in discriminating loess landform types. Tang et al. (2008) defined such a histogram as a slope spectrum and the method as the slope spectrum method, a new methodology to quantitatively study the landforms of the Loess Plateau. This methodology also represents the spatial distribution of loess landforms and can be adapted to investigate the variability of terrain features in different evolutionary phases of loess landforms.

From a geomorphological perspective, each landform type has certain similarities both in its topographic structures and geomorphological features (Davis, 1899). Such similarities have been used as a quantitative representation via the slope spectrum as well as in the regional slope stability model (Rowbotham, 1998; Vanacker et al., 2003). However, the existence of the slope spectrum has an essential condition, namely, the histogram should remain consistent in various test areas. Therefore, it is essential that with the increase in test areas, the derived histogram becomes more and more stable in its distribution. The area of the stable histogram is defined as the slope spectrum critical area (SSCA). SSCA is not only the basis for a corrective slope spectrum derivative but may also be a potentially valuable clue in revealing the phases of geomorphological evolution.

This paper focuses mainly on the method of extracting SSCA based on grid DEMs, as well as the spatial distribution pattern of the SSCA in the Loess Plateau area. Furthermore, a deeper discussion explores the geographical significance of SSCA.

\section{Test area and data}

Forty-eight sites, randomly distributed in Northern Shaanxi, the core region of the Loess 
Plateau, were selected as key test areas (Figure 1). Each site consisted of specific loess landforms and had an area of approximately $100 \mathrm{~km}^{2}$. The corresponding DEMs were prepared with a grid size of $5 \mathrm{~m}$, produced from the contours of topographic maps.

The loess cover thickness of this area gradually increases from north to south, with a range of approximately 50 to $200 \mathrm{~m}$. In addition, rainstorms are concentrated in the summer season, and the main vegetation cover consists of shrubs, grass and wood forests. Dry land, accelerated soil erosion, and high sediment yield are serious problems in this area (Zhou et al., 2011).

To investigate the spatial distribution pattern of SSCA in the Loess Plateau, eight representative test areas in northern Shaanxi, forming a longitudinal section from north to south, were selected as key test areas in which many small watersheds will be delineated to verify the stability of the slope spectrum (Table 1).

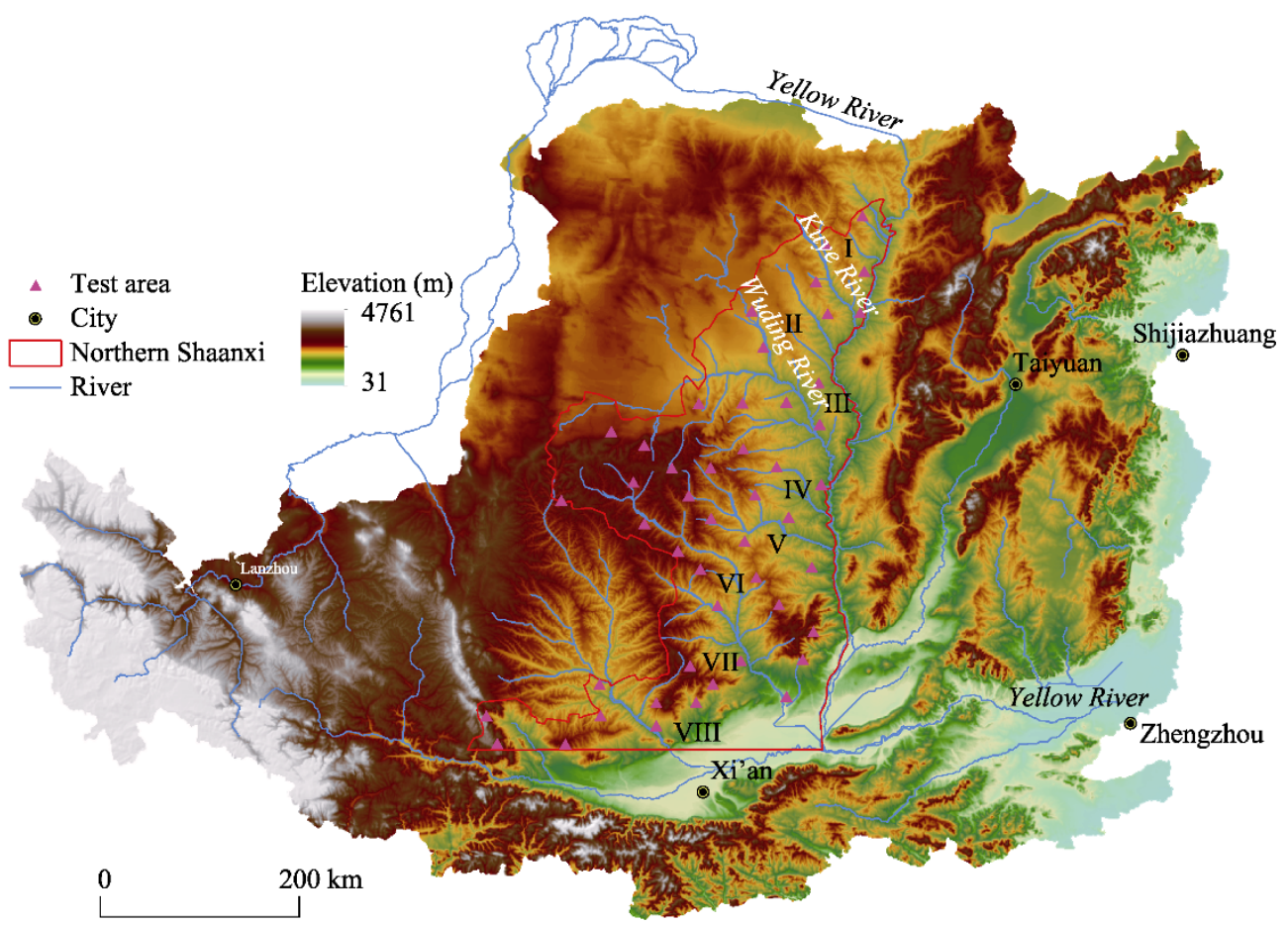

Figure 1 Location of the study area and distribution of test sites. The eight test areas are labeled in black corresponding numbers with white background: (I) Shenmu, (II) Yulin, (III) Suide, (IV) Yanchuan, (V) Yanan, (VI) Ganquan, (VII) Yijun and (VIII) Chunhua

Table 1 Parameters of elevation data on experimental plots

\begin{tabular}{clcccc}
\hline \multirow{2}{*}{ Site } & Area name & \multicolumn{4}{c}{$1: 10,000$ DEM } \\
\cline { 3 - 6 } & & Minimum $(\mathrm{m})$ & Maximum $(\mathrm{m})$ & Mean $(\mathrm{m})$ & Standard deviation $(\mathrm{m})$ \\
\hline I & Shenmu & 1005 & 1322 & 1197.92 & 49.95 \\
II & Yulin & 1110 & 1310 & 1212.20 & 37.27 \\
III & Suide & 814 & 1188 & 995.35 & 62.10
\end{tabular}




\begin{tabular}{clrrrr} 
IV & Yanchuan & 922 & 1251 & 1088.92 & 61.14 \\
V & Yanan & 990 & 1404 & 1196.86 & 79.45 \\
VI & Ganquan & 1151 & 1432 & 1296.00 & 55.87 \\
VII & Yijun & 761 & 1158 & 986.09 & 73.08 \\
VIII & Chunhua & 768 & 1188 & 1044.75 & 75.27 \\
\hline
\end{tabular}

\section{Methodology}

\subsection{Test area}

As illustrated above, the SSCA can be described as the area in which the slope spectrum becomes stable. Hence, along with an increase in the test area, the changing shape of slope spectrum or a specific parameter would continue to be measured until the rate of change of the spectrum is below a specific value. This value is SSCA, as influenced by the extraction method.

There are two types of extraction method to determine SSCA proposed in literatures (Figure 2). The first method is based on an $N$ by $N$ neighborhood statistic window. As the window increases, the spectrum from an $N$ by $N$ slope matrix dataset of DEMs gradually approaches its final stable status. Although this method is quick and easy to implement, such an artificial rectangle cannot describe the practical distribution of the surface, especially for anisotropic terrain.

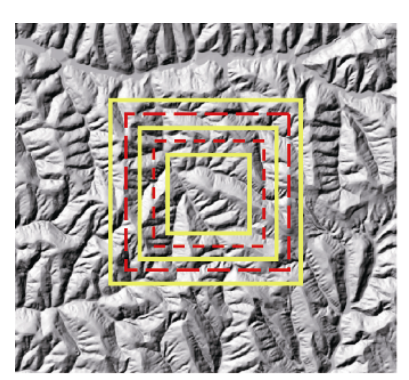

(a) Rectangular window

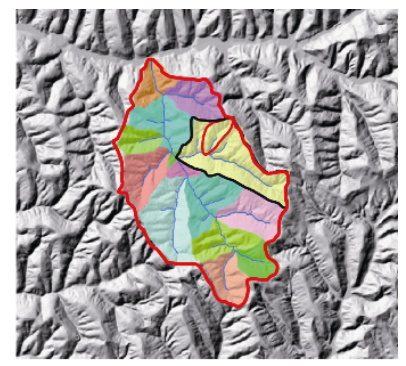

(b) Catchment unit

Figure 2 Two different test areas in extracting SSCA

Another method for extracting SSCA is based on catchment units, which are natural geomorphological units. As the catchment class or the catchment area increases, the corresponding flow-accumulation threshold would also increase. In this process, the distribution of the slope histogram has a tendency to stabilize. When the variation in the slope spectrum drops to a relatively low level, its quantitative value can be recorded and defined as the critical value for the existing slope spectrum. Because this method uses natural catchment as an analysis window, it is a proper way to extract SSCA and may represent the inherent association between SSCA and the minimal geographical unit. Hence, this method is adopted in this paper for the discussion of the minimal geographical unit.

\subsection{Extraction procedure}

The procedure for extracting SSCA based on drainage networks is shown in Figure 3. At the 
beginning of this process, drainage networks should first be extracted from a DEM. The general procedures for drainage extraction from DEM data include: (1) pit filling, (2) flow direction calculation, and (3) computing the contributing area draining to each grid cell. The flow accumulation grid can be used to delineate drainage networks based on a threshold for accumulation value, one of the first and simplest flow-related quantities computed from a DEM. This layer, which contains numerous watersheds, is a drainage network extracted by the D8 model in the DEM. In this step, watersheds of various shapes and sizes will be extracted by different accumulation values. The larger threshold value input, the larger each watershed area will be.

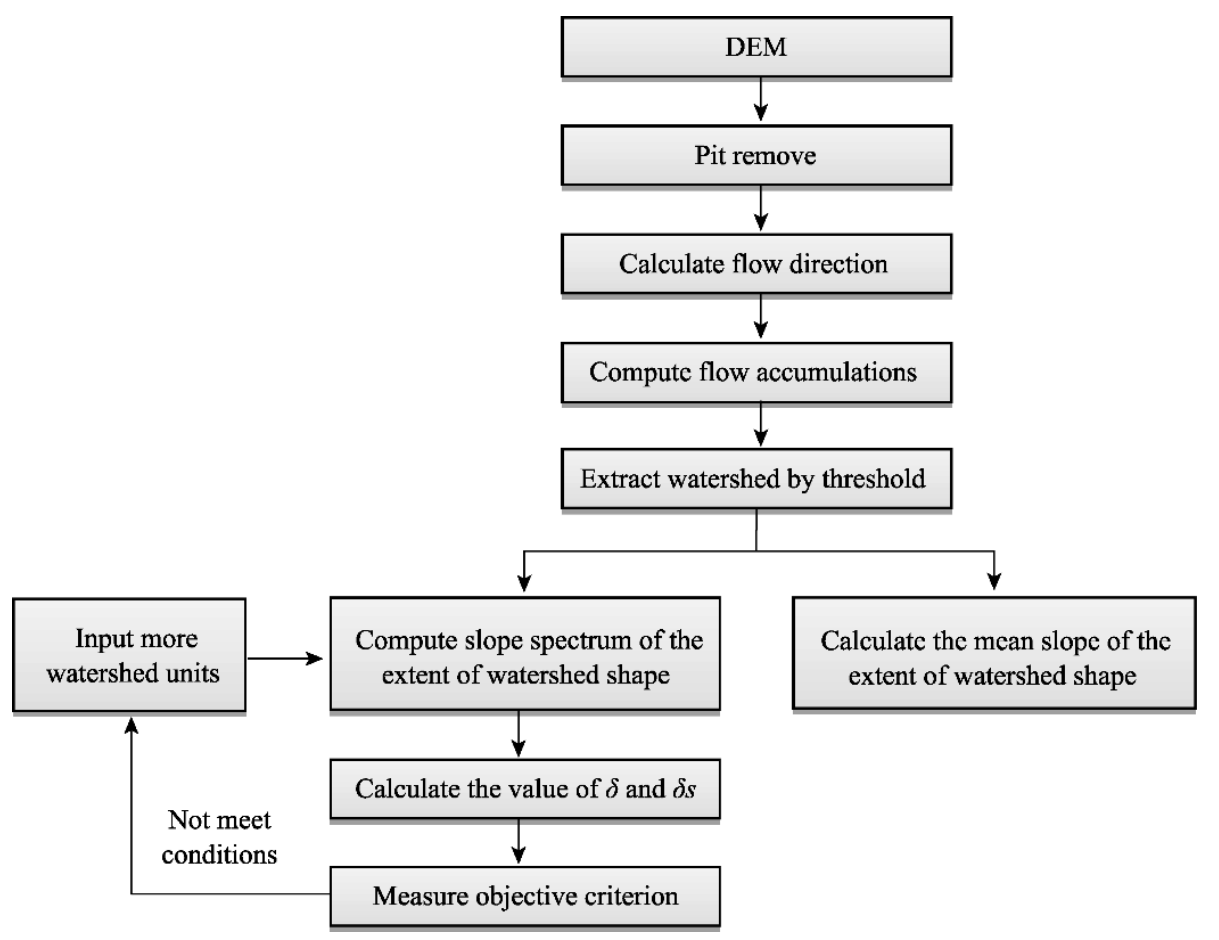

Figure 3 The procedure for the extraction of SSCA

Afterwards, the slope matrix based on the original DEM is calculated; meanwhile, each slope spectrum within a specific catchment can be obtained using an overlap calculation. Slope gradient is calculated using grid-based algorithm developed by Zevenbergen and Thorne (1987). In the next step, the degree of stability of these slope spectra (hereafter referred to as the "current spectrum") will be evaluated by its similarity to a reference slope spectrum. Here, the reference is defined as a slope spectrum extracted from a certain landform area with adequate acreage (approximately $100 \mathrm{~km}^{2}$ ) (Tang et al., 2008).

In generating a slope spectrum, a $3^{\circ}$ equal interval slope classification is frequently adopted, which has proven to be suitable for the loess area (Wang, 2005; Tang et al., 2008). Some quantitative indicators of similarity are proposed for the comparison between the reference and current slope spectra. The area percentage is defined as the quotient of the slope amount divided by area as follows:

$$
P i=\text { Count } / S
$$

where count is the slope amount with the same classification of slope spectrum, and $S$ is the 
size of the test area. The indicator of the maximum is the difference between the maximum value of the current and referenced slope spectra, and the function takes the form:

$$
\delta=\operatorname{Abs}\left(\operatorname{Max}\left(P_{r i}\right)-\operatorname{Max}\left(P_{c i}\right)\right)
$$

where $P_{r i}$ and $P_{c i}$ are percentages representing the reference and current slope spectra, respectively, $\operatorname{Max}(\mathrm{)}$ is a function to compute the maximum value, and $\operatorname{Abs}()$ is the absolute value of a given variable. Another indicator of slope spectrum has the form:

$$
\delta_{s}=\sum_{i=1}^{30} \operatorname{Sum}\left(\operatorname{Abs}\left(P_{r i}-P_{c i}\right)\right)
$$

The procedure for judgment of stability can be summarized as follows: all parameters extracted from all small watersheds and the entire test region meet the condition of Eq. (4).

This procedure reflects the similarity of adjacent landforms and is based on the extension of watershed units. In this paper, we set parameters $a=0.001, b=0.001$ and $n=30$. Under these limitations, the SSCA is suitable and accurate, as the slope spectrum in neighboring windows has a similarity of $99 \%$ when the test area is larger than SSCA (Li, 2007).

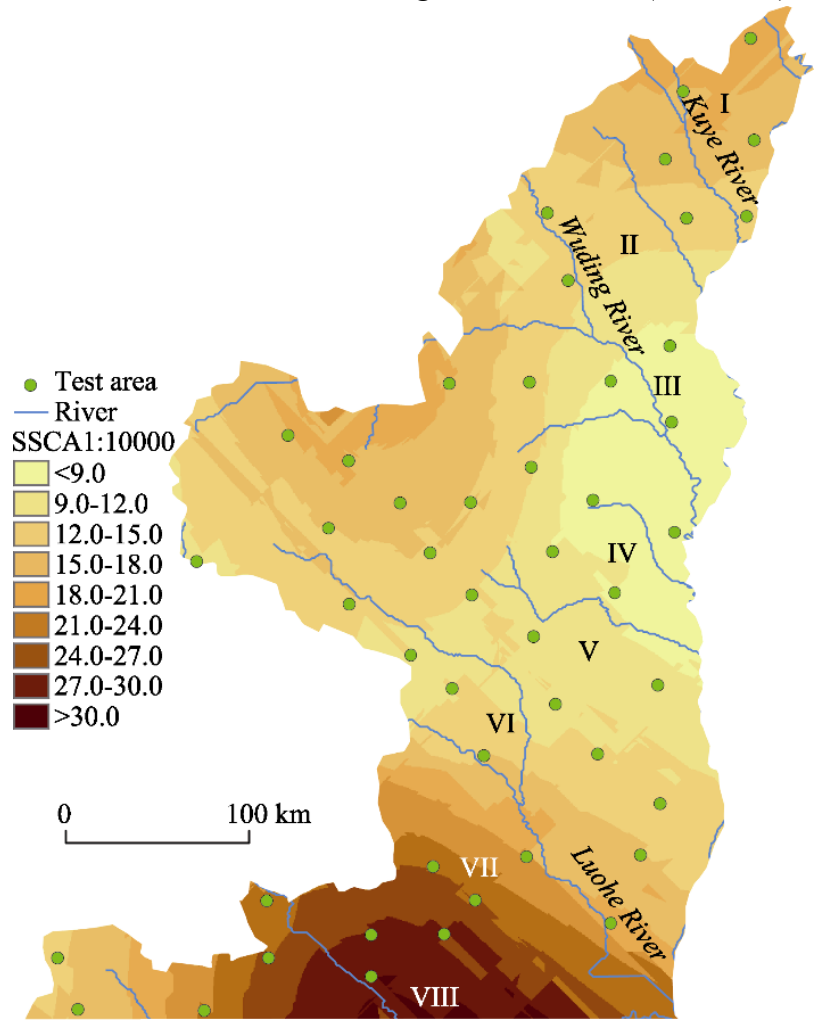

Figure 4 Spatial distribution of SSCA in northern Shaanxi

In addition, eight areas with typical loess landforms were selected to verify the existence of SSCA in watersheds. Standard techniques for DEM preparation include pit filling; the calculation of flow direction, which is computed with the D8 algorithm (O'Callaghan et al., 1984); and flow accumulation grids. After inputting the proper threshold of accumulation, 
plenty of small watersheds might be seen as independent natural landscape units that could be extracted by the accumulations. Meanwhile, the mean slope within each unit has been calculated. Thus, thousands of statistical samples from each test area have been extracted to correctly investigate the trend of the mean slope on a large scale.

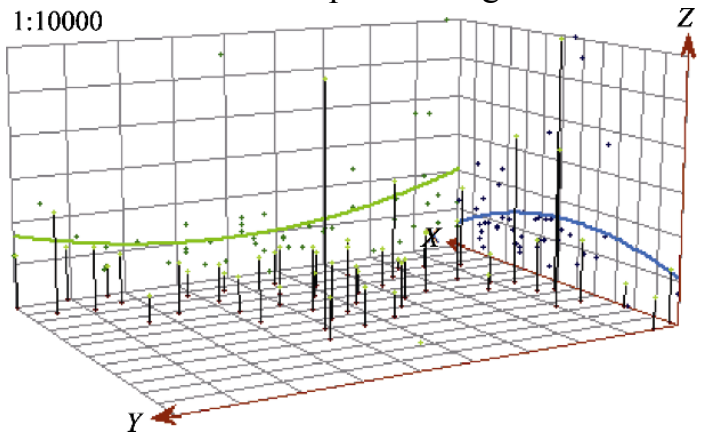

Figure 5 The trend of SSCA variation in northern Shaanxi loess area

\section{Results}

\subsection{Spatial distribution of slope spectrum critical area}

The value of SSCA in each test area can be achieved by aforementioned method, and its spatial distribution in the northern Shaanxi Loess Plateau area is shown in Figure 4. As seen in this figure, the values of SSCA for different landforms present a specific spatial distribution pattern. The maximum appears near site VIII with a value of $35.1 \mathrm{~km}^{2}$ and the minimum at site III with a value of $6.18 \mathrm{~km}^{2}$. Across northern Shaanxi from north to south, the landform types include loess meadow-basin, loess-low-hill, loess deep incision gorge-hill, loss ridge-low-mountain, loess hill-ridge, loess tableland-ridge, loess tableland, loess middlelow mountain, and loess platform-tableland, indicating the variation in the landform from flat to fragmental to flat again. SSCA presents a trend of high-low-high, coinciding with the terrain fluctuation. This tendency might suggest an interesting finding that SSCA shows a strong correspondence with the evaluation of loess terrain. Namely, in the primary stage of loess landform evaluation, the existence and development of a loess gully is usually determined by disorder, i.e., a gully on the surface of loess tableland. Nevertheless, in the middle stage, the loess terrain possesses rather high similarity, and SSCA appears relatively low in this region, i.e., in the area of site III.

The variation of SSCA in different directions was investigated via the geo-statistical tool in ArcGIS 10. As shown in Figure 5, the SSCA for northern Shaanxi shows a "U-shaped" trend from north to south and an inverted "U-shaped" trend from east to west. The erosion intensity of the loess surface shows a regular weak-strong-weak pattern from north to south in northern Shaanxi, which leads to various physiographies, as well as various slope gradient compositions for each landform (Zhou et al., 2011). The rougher the surface is, the lower SSCA will be. 


\subsection{Existence of geomorphological units}

The formation of a watershed is determined by unified features of the physical processes. An independent watershed is a combination of river and slope (Vanacker et al., 2003; Zhou et al., 2006b). Hence, there exist certain interrelations and mutual restraints between the landscape elements in any basin. Thousands of small watersheds of different sizes are selected as the basic units for the study of landform development on the basis of independent geomorphological units. We calculate eight typical scatter plots, including the mean slopes of geomorphological units, to compare the stability of the slope spectrum with SSCA for a large number of independent geomorphological units. It is noted that there are at least 10,000 statistical samples in each test area. Then, the mathematical relationships of the areas of the independent geomorphological units and mean slope values can be achieved.I 


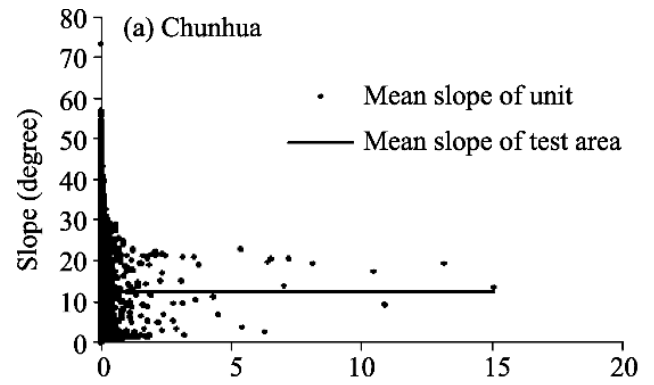

Area of independent landform unit $\left(\mathrm{km}^{2}\right)$
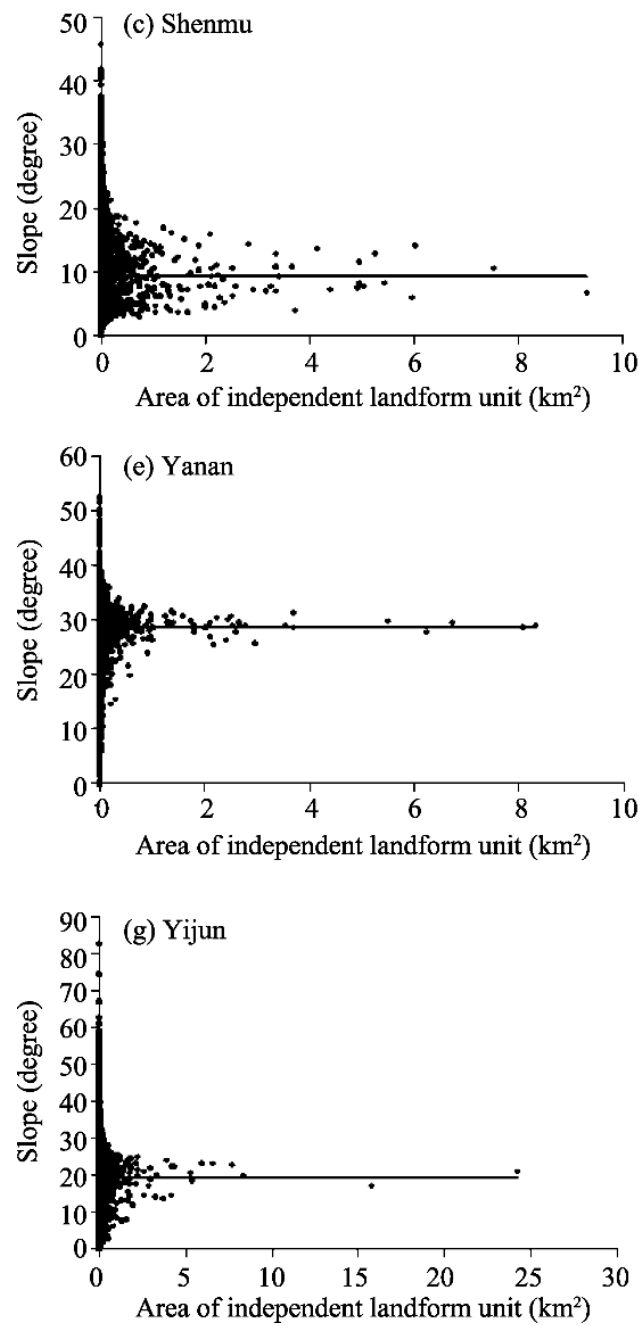

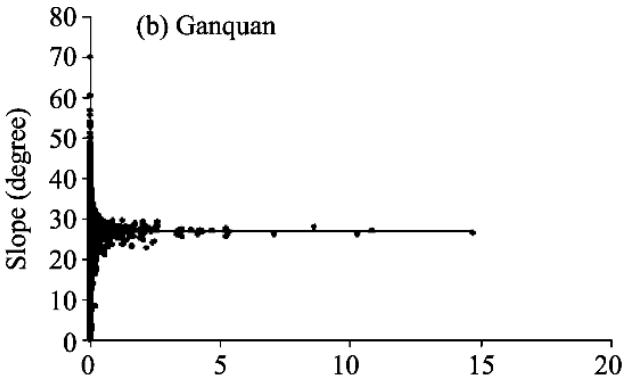

Area of independent landform unit $\left(\mathrm{km}^{2}\right)$
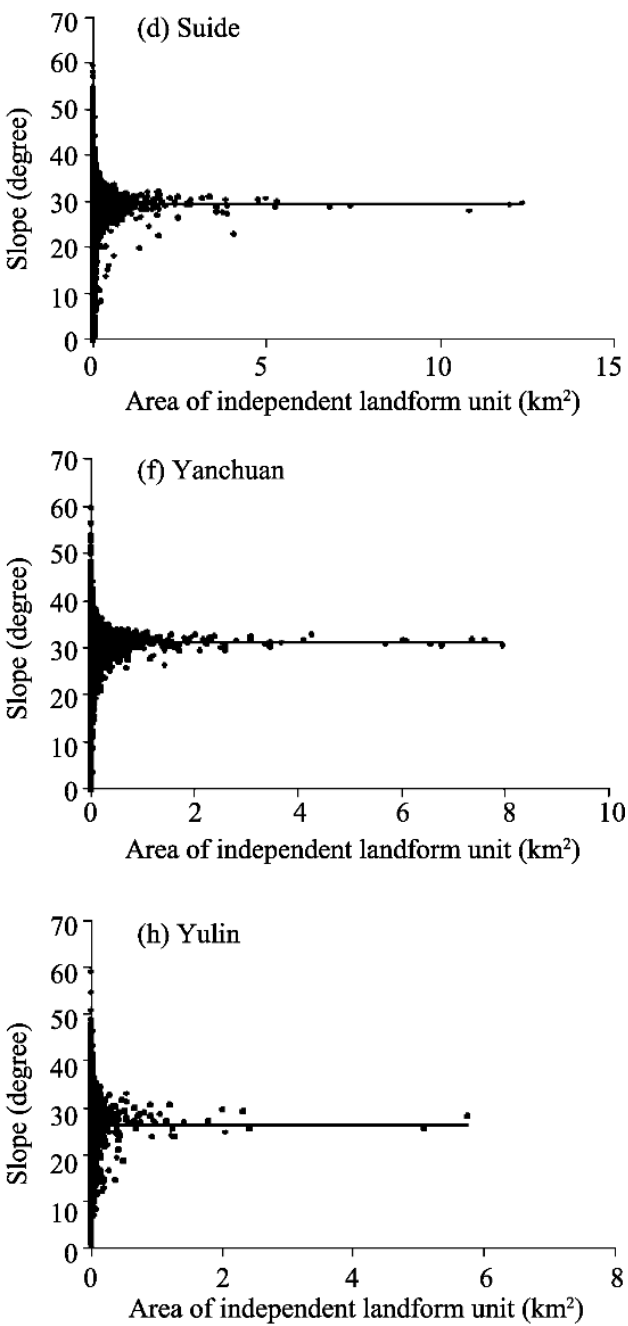

Figure 6 Scatter plot of every area of independent natural landscape unit and its mean slope

Figure 6 shows the scatter plots of independent natural landscape units with their mean slopes, where the straight line on each scatter plot is the mean value of all units in a test area. As seen in this figure, the mean slope values of watersheds in the test areas gradually shrink to a certain value. The mean slope of the independent units in the desert-loess transitional area (site I), southern loess ridge-low-mountain (site VII) and loess tableland-ridge (site VIII) are discrete. The main reason for this phenomenon is that these test areas are flat and unbroken. 
In other words, these independent physiographic units do not include all types of relief within a basin; when the coverage areas of each relief type are significantly random, a geographical unit may only contain loess interfluves or gully-slope lands. Therefore, the mean slopes in these independent units do not show any trends. As area increases, independent geographical units will likely still include a few instances of relief. These synthetic results may cause the mean slopes to not obviously converge.

It can also be seen that in the center of northern Shaanxi, some test areas, such as sites III, IV, V and VI, which are loess hill-ridges, show an obvious trend in which the mean slopes converge toward the mean slope value of all units with increasing independent geographical units. The main reason might be that terrain in these areas is complicated, with many gullies. Each unit includes complex relief and relatively unbroken small watersheds.

The existence of SSCA could be proved by the tendency of the mean slope based on the statistics of small watersheds. This uncertainty in the slope spectrum leads to the instability of the mean slope, reflecting the variable curve fluctuation of the slope spectrum. Hence, the slope spectrum may also have various features under different landforms. In addition, the size of the stable development area of each landform could be determined using this method.

Thus, the larger the landscape test area a unit has, the more stable slope spectrum information we can ascertain. Through the analysis of these diagrams, we can be sure that SSCA could be used as an efficient indicator to determine the minimum size of the physiographic unit.

\subsection{SSCA of typical landforms}

Six sample sites were selected in Shaanxi Province in China, which contains typical landforms (Table 2). With finer resolution, DEM could reflect more topographic information, showing minute fluctuations of micro surfaces. Furthermore, the tendency of the landscape evolution might be determined by this fluctuation. The SSCAs of the loess hill and loess hillridge are smaller than those of the loess tableland, in which the undulations of relief are gentle, and most parts in the middle of these areas are flat. With the gentle undulations, the erosion intensity is increasing slowly. Hence, the SSCA of site VIII is affected most obviously by the relief and has the highest value among these test areas, whose terrain fluctuations are gentler than those of others. Even if the SSCAs of different landforms are extremely diverse, adjacent areas with the same landscape have approximately the same SSCAs.

Table 2 Statistics of SSCA of typical landforms

\begin{tabular}{clcl}
\hline Site & Area name & SSCA $\left(\mathrm{km}^{2}\right) 1: 10,000$ & Landform types \\
\hline I & Shenmu & 13.29 & Loess deep incision gorge-hill \\
III & Suide & 8.21 & Loess hill-ridge \\
IV & Yanchuan & 10.08 & Loess hill-ridge \\
VI & Ganquan & 10.60 & Loess ridge-low-mountain \\
VII & Yijun & 13.21 & Loess tableland \\
VIII & Chunhua & 35.01 & Loess middle-low mountain, loess platform-tableland \\
\hline
\end{tabular}

\section{Discussion}


It is noted that slope spectrum is a fundamental representation of loess landscape evolution and could be applied to determine the stage of the geographical cycle. By extending the study area, the homogeneous textures are enhanced. According to the first law of geography, the same landform should possess the same or approximately the same slope composition (i.e., slope spectrum). It has been proven that slope spectrum can be employed for the interpretation of loess landscape, as well as to evaluate the landform evolution of the Loess Plateau (Tang et al., 2008). Nevertheless, the experiments in this paper show that SSCA could be another valuable index for revealing the mechanism of loess landforms in the plateau.

Scores of terrain variables were used in the study to investigate the main factors affecting the intensity and spatial distribution of SSCA. By comprehensively considering the mechanism, dependency and algorithm etc., four indices, gully density, skewness of the slope spectrum $(S)$, terrain dynamic force $\left(T_{d}\right)$ and slope of slope (SOS), have been chosen to quantitatively depict the relationships between geomorphological properties and SSCA.

Table 3 Algorithms for slope spectrum indices

\begin{tabular}{|c|c|c|c|}
\hline Indicators & Algorithms & Units & Significance \\
\hline Gully density & $\begin{array}{l}D=\frac{\sum L}{A} \\
\Sigma L: \text { The gully distance in watershed } \\
A: \text { The area of watershed }\end{array}$ & $\mathrm{km} / \mathrm{km}^{2}$ & $\begin{array}{l}\text { Reflecting the fragmentation of the } \\
\text { surface }\end{array}$ \\
\hline $\begin{array}{l}\text { Skewness of the } \\
\text { slope spectrum }(S)\end{array}$ & $\begin{array}{l}S-\sqrt{\frac{1}{6 n}} \sum_{i=1}^{n}\left(\frac{P_{t}-\bar{P}}{\sigma}\right)^{2} \\
P \text { :Mean frequency } \\
\sigma: \text { Standard deviation }\end{array}$ & Unitless & $\begin{array}{l}\text { Reflecting the distribution of slope } \\
\text { gradient combination }\end{array}$ \\
\hline $\begin{array}{l}\text { Terrain dynamic } \\
\text { force }\left(T_{d}\right)\end{array}$ & $\begin{array}{l}\left.T_{d}-\sum_{i=1}^{m}\left(\left(\sum_{j=1}^{n} \sin \alpha_{\frac{H}{2}}\right) / n\right) \times P_{i}\right) \\
P_{i}: \text { Frequency of each slope class } \\
a_{i j}: \text { Slope gradient of grid } i j \\
j: \text { Number of grid for slope class } i\end{array}$ & Unitless & $\begin{array}{l}\text { Reflecting the erosional potential by } \\
\text { the terrain }\end{array}$ \\
\hline $\begin{array}{l}\text { Slope of slope } \\
(S O S)\end{array}$ & $\begin{array}{l}\text { slopevari }=\arctan \sqrt{f_{x}^{2}+f_{y}^{2}} \\
f_{x}: \text { The variation rate of slope along } \mathrm{x} \text { axis } \\
f_{y}: \text { The variation rate of slope along y axis }\end{array}$ & Unitless & $\begin{array}{l}\text { Reflecting the complexity of the } \\
\text { surface }\end{array}$ \\
\hline
\end{tabular}

Gully density is usually an indicator that reveals the development stage of a loess watershed (Jing, 1986; Zhang et al., 1998; Tucker et al., 2001). Slope spectrum, the histogram of slope grades, is proven to be an effective method for representing the combination of loess surfaces. As a key index, the skewness of slope spectrum mainly statistically and macroscopically reveals the steepness. $T_{d}$ is a ratio of the sum of the horizontal component force of gravities to the area of the watershed, which could represent the contribution of the terrain to erosion (Li et al., 2006, Li et al., 2007; Tang et al., 2008). SOS means slope of slope, representing the variation in slope gradient, and its statistical values can reveal the complexity and roughness of the surface to some extent. Table 3 shows the algorithms for calculating these indices.

The correlations between SSCA and gully density, $S, T_{d}$ and SOS are given in Figure 7. There exists a good exponential relationship between SSCA and gully density, $T_{d}$ and SOS, and a logarithmic relationship between SSCA and $S$. The relationship between SSCA and gully density is negative. SSCA shows a good logarithmic function with $S$ and will increase with an increase in $S$ values. The highest determination coefficient is 0.7782 , which is 
achieved between gully density and SSCA, followed by $T_{d}$ and SSCA with a value of 0.6288 . It is suggested that all of these indices have a significant correlation with SSCA and thus could be employed to reveal its geographical indication.
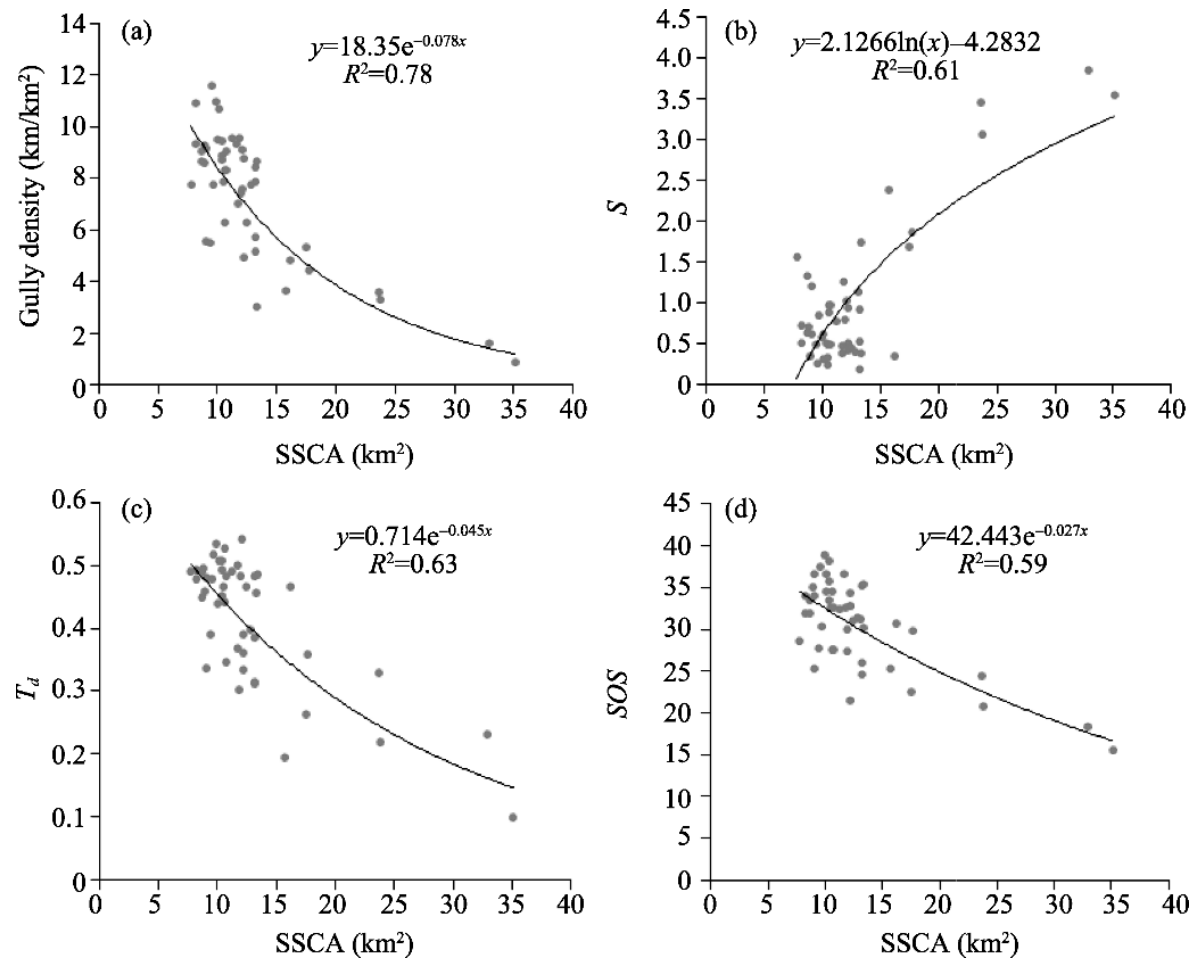

Figure 7 Plots of SSCA vs. gully density, $S, T_{d}$ and $S O S$ in the Loess Plateau $\left(R^{2}\right.$ denotes the coefficient of determination)

The spatial variations of auxiliary indices described in Table 4 are also given in Figure 8 . Generally, the landform types of the Loess Plateau vary in a sequence from north to south, i.e., loess low-hill, loess-hill, loess hill-ridge, loess ridge-hill and loess tableland. The gully density, $T_{d}$ and $S O S$ change from low to high, then to low again, showing a similar variation trend with terrain roughness, in spite of the inverse skewness. Figure $8 \mathrm{~b}$ shows that the range of skewness is from 0.196 to 0.057 in the northern Shaanxi test areas, and its mean value is 1.256, approaching a normal distribution pattern ( $\mathrm{Li}, 2007)$. The relatively high values appear mainly in the southern loess tableland and loess meadow-basin, where surfaces are smooth, with the slope gradient ranging from $0^{\circ}$ to $12^{\circ}$, showing a positive skewness in the slope spectrum. 

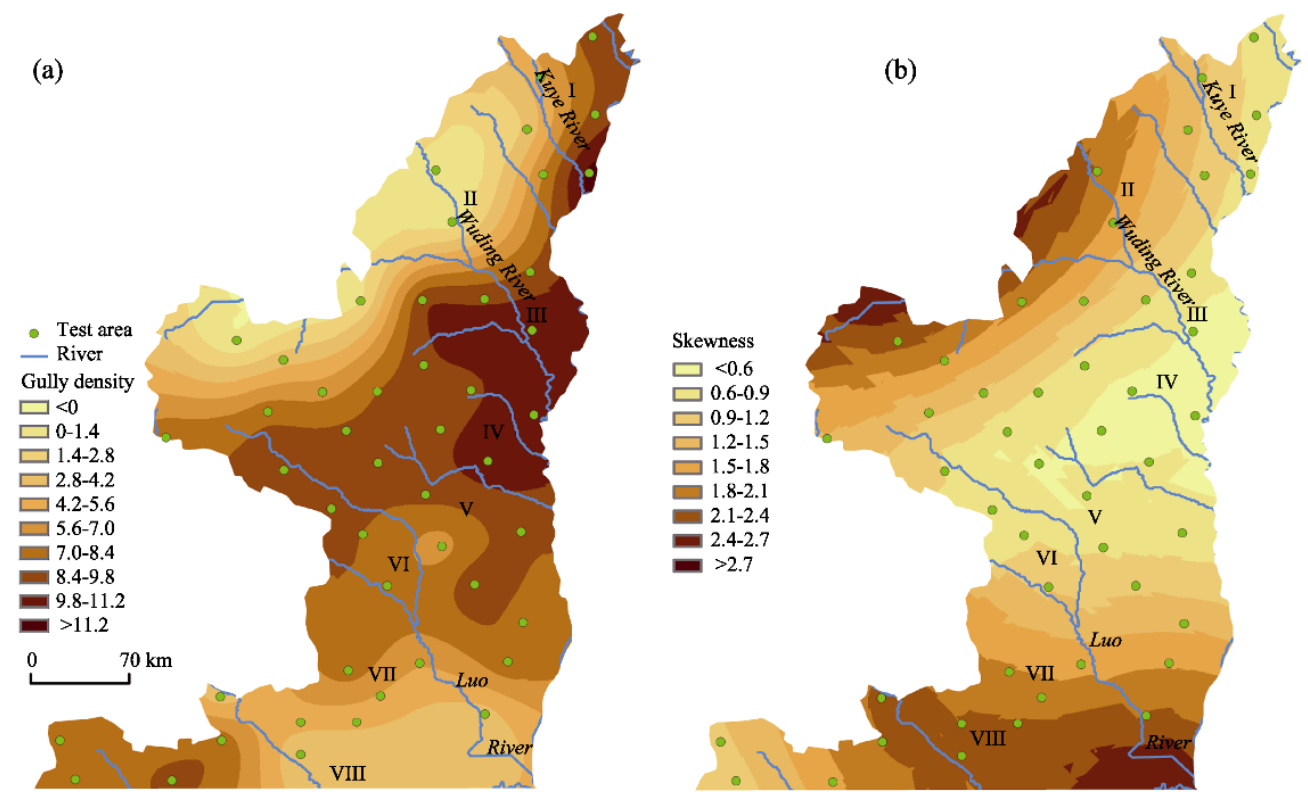

(c)

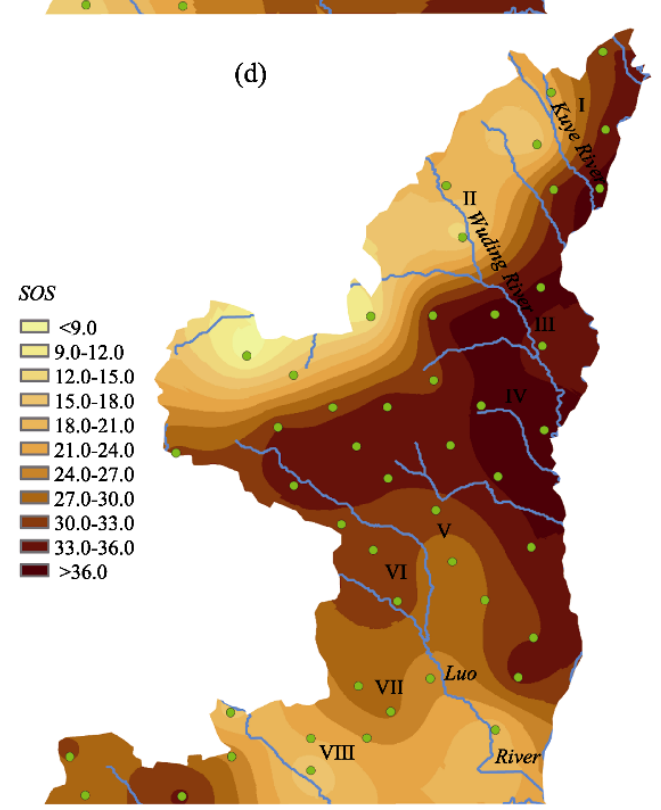

Figure 8 Spatial distribution of the slope spectrum indices in northern Shaanxi

From north to south, the high values of $T_{d}$ mainly appear in the middle of northern Shaanxi. It is this area that produces the major sediment load for the lower reaches of the Yellow River via a few tributaries, including the Kuye River, Tuwei River, etc. The maximum values exist in sites III and IV, as shown in Figure 8c. The maximum values of $S O S$ are located in the triangular region where the vertex is Ansai, i.e., sites III and IV, where landforms are dominated by loess hill-ridge. Analyzed together with Figure 8a, it is suggested that the terrains of these areas are complicated and suffer from serious and wide gully erosion. This is indirect evidence in support of Jiang's (1966) result.

Simultaneously, landform evolution of the Loess Plateau and soil erosion are interrelated as cause and effect. The process of landform evolution can be classified into the following stages: 
inheritance, reformation and late evolution (Ma, 1996), which are greatly affected by the intensity of erosion. These four indicators are directly related to the spatial distribution of loess landforms, including loess tableland, loess ridge, loess hill and so on, and could depict terrain relief as well as erosion intensity from a geomorphological viewpoint. The similar spatial fluctuation of these indicators from south to north also shows an obvious spatial variation of surface roughness in this area. Combining Figures 4 and 8 , we can conclude that the SSCA could be used to represent the spatial variation of terrain relief, as the spatial variation of gully density, SOS and $T_{d}$ are significantly correlated with SSCA. This is of great significance in describing the surface roughness and geomorphological evolution. It provides a theoretical basis for loess landform classification based on SSCA that is related to these indicators.

With the aggravation of soil erosion and the sharp undulation of loess terrain, the values of gully density, $T_{d}$ and $S O S$ are increasing in the southern part of the test area. Along with the development of loess landforms, the loess tablelands will be gradually eroded to tattered loess tableland, loess ridges, and typical loess hills. In general, the changing trend is that the soil loss aggregates with the increase of slope gradient, even though there is a slight disparity in soil loss under the same topographic condition (Xu et al., 2009). A comprehensive analysis of the above discussion concluded that SSCA could be accepted as a discriminating factor in identifying loess landforms. Furthermore, SSCA represents, to some extent, the degree of landform development. SSCA values achieve a maximum in the early stages of loess landform development, i.e., loess tableland in the south of northern Shaanxi, and reach their bottom values in the middle stage of loess terrain evolution, i.e., loess hilly-gullied terrain, located mainly in the center of the study area.

\section{Conclusions}

Slope spectra have been widely utilized as indicators of terrain roughness and the relief of loess landforms. Based on the mean slope statistics in eight representative areas, this paper found that a necessary condition for the existence of slope spectrum is SSCA, namely, the critical area in which the slope histogram becomes stable. We argue strongly that this condition is necessary for four reasons:

(1) Generally, SSCA values are obviously different in areas of different loess landforms, such as loess tableland and loess hills. The more complex the loess terrain is, the lower SSCA values will be.

(2) Experimental results show that SSCA is significantly correlated with gully density, SOS, slope skewness and $T_{d}$, four selected core terrain factors of loess landforms. SSCA may reflect the development stage of loess landform evolution; hence, it should be a novel and highlighted index in geomorphological studies.

(3) The stability area of slope spectrum is obviously dependent on the DEM scale and is reflected by topographic complexity. In the study plots, the size of the SSCA is closely related to the specific topography and the qualification of slope spectrum's stability. Moreover, the SSCAs of different landform types, even some of the same landform types, are generally inconsistent. However, for the same landform region, when the test areas include enough information on landform features, we can always find the critical area of the stable slope 
spectrum.

(4) The spatial variation of SSCA is one of the main indications of water and soil erosion's spatial performance. SSCA can reveal the objective laws of a river basin's geomorphological evolution effectively, improving the qualitative description of the river basin's geomorphological evolution and topographic elements by making it more quantitative.

More work is necessary to deeply and comprehensively investigate the geomorphological significance of SSCA, especially its universality in geographical and geomorphological research.

\section{References}

Ayalew L, Yamagishi H, 2004. Slope failures in the Blue Nile basin, as seen from landscape evolution perspective. Geomorphology, 57(1/2): 95-116.

Chen Liding, Huang Zhilin, Gong Jie et al., 2007. The effect of land cover/vegetation on soil water dynamic in the hilly area of the Loess Plateau, China. Catena, 70(2): 200-208.

Cheng Weiming, Zhou Chenghu, 2014. Methodology on hierarchical classification of multi-scale digital geomorphology. Progress in Geography, 33(1): 23-33. (in Chinese)

Davis W M, 1899. The geographical cycle. Geographical Journal, 14: 481-504.

He Xiubin, Li Zhanbin, Hao Mingde et al., 2003. Down-scale analysis for water scarcity in response to soil-water conservation on Loess Plateau of China. Agriculture, Ecosystems \& Environment, 94(3): 355-361.

Hessel R, van Asch T, 2003. Modelling gully erosion for a small catchment on the Chinese Loess Plateau. Catena, 54(1/2): 131-146.

Hughes M W, Almond P C, Roering J J et al., 2010. Late Quaternary loess landscape evolution on an active tectonic margin, Charwell Basin, South Island, New Zealand. Geomorphology, 122(3/4): 294-308.

Iwahashi J, Watanabeb S, Furuya T, 2001. Landform analysis of slope movements using DEM in Higashikubiki area, Japan. Computers \& Geosciences, 27(7): 851-865.

Jiang Deqi, Zhao Chengxin, Chen Zhanglin, 1966. Research on the sediment source in middle reaches of Yellow River. Acta Geographica Sinica, 31(1): 20-36. (in Chinese)

Jing Ke, 1986. A study on gully erosion on the Loess Plateau. Scientia Geographica Sinica, 6(4): 340-347. (in Chinese)

Li Fayuan, 2007. Research on the slope spectrum and its spatial distribution in the Loess Plateau [D]. Nanjing Normal University, 55-70. (in Chinese)

Li Fayuan, Tang Guoan, 2006. DEM based research on the terrain driving force of soil erosion in the Loess Plateau. In: Geoinformatics 2006: Geospatial Information Science, Proc. of SPIE, 2006, 6420, Reston, Virginia, USA.

Li Fayuan, Tang Guoan, Wang Chun et al., 2007. Quantitative analysis and spatial distribution of slope spectrum: A case study in the Loess Plateau in north Shaanxi province. In: Chen J M, Pu Y X, eds. Proceedings or SPIEGeoinformatics 2007: Geospatial In-formation Science. Bellingham: SPIE, 2007.

Liang Guanglin, Chen Hao, Cai Qiangguo et al., 2004. Research progress of modern topographic evolvement and landform erosion in Loess Plateau. Research of Soil and Water Conservation, 11(4): 131-137. (in Chinese)

Luo Laixing, 1956. A tentative classification of landforms in the Loess Plateau. Acta Geographica Sinica, 22(3): 201-222. (in Chinese)

Matsushi Y, Matsuzaki H, 2010. Denudation rates and threshold slope in a granitic watershed, central Japan. Nuclear Instruments and Methods in Physics Research Section B: Beam Interactions with Materials and Atoms, 268(7/8): 1201-1204.

Ma Naixi, 1996. Relationship between loess geomorphic evolution and soil erosion. Bulletin of Soil and Water Conservation, 16(2): 6-10. (in Chinese)

McBride R A, Taylor M J, Byrnes M R, 2007. Coastal morphodynamics and Chenier-Plain evolution in southwestern Louisiana, USA: A geomorphic model. Geomorphology, 88(3/4): 367-422. 
O'Callaghan J F, Mark D M, 1984. The extraction of drainage networks from digital elevation data. Computer Vision, Graphics and Image Processing, 28(3): 323-344.

Rowbotham D N, Dudycha D, 1998. GIS modelling of slope stability in Phewa Tal watershed, Nepal. Geomorphology, 26(1-3): 151-170.

Shary P A, Sharayab L S, Mitusov A V, 2002. Fundamental quantitative methods of land surface analysis. Geoderma, 107(1/2): 1-43.

Shi Hui, Shao Mingan, 2000. Soil and water loss from the Loess Plateau in China. Journal of Arid Environments, 45(1): 9-20.

Tang Guoan, Li Fayuan, Liu Xuejun et al., 2008. Research on the slope spectrum of the Loess Plateau. Science in China (Series E: Technological Sciences), 51(1): 175-185.

Tang Guoan, Zhao Mudan, Li Tuanwen et al., 2003. Simulation on slope uncertainty extracted from DEMs at different resolution levels: A case study in the Loess Plateau. Journal of Geographical Sciences, 13(4): 387-394.

Tong Chiming, Zhou Chenghu, Cheng Weiming et al., 2014. Morphological characteristics and developmental stages of loess tablelands based on DEM. Progress in Geography, 33(1): 42-49. (in Chinese)

Tucker G E, Catani F, Rinaldo A et al., 2001. Statistical analysis of drainage density from digital terrain data. Geomorphology, 36(3/4): 187-202.

Vanacker V, Vanderschaeghe M, Govers G et al., 2003. Linking hydrological, infinite slope stability and land-use change models through GIS for assessing the impact of deforestation on slope stability in high Andean watersheds. Geomorphology, 52(3/4): 299-315.

Wang Chun, 2005. The uncertainty of slope spectrum derived from DEM in the Loess Plateau of northern Shaanxi province [D]. Northwest University, 86-94. (in Chinese)

Xiong Liyang, Tang Guoan, Li Fayuan et al., 2014a. Modeling the evolution of loess-covered landforms in the Loess Plateau of China using a DEM of underground bedrock surface. Geomorphology, 209: 18-26.

Xiong Liyang, Tang Guoan, Yuan Baoyin et al., 2014b. Geomorphological inheritance for loess landform evolution in a severe soil erosion region of Loess Plateau of China based on digital elevation models. Science China Earth Sciences, 57(8): 1944-1952.

Xu Yong, Yang Bo, Liu Guobin et al., 2009. Topographic differentiation simulation of crop yield and soil and water loss on the Loess Plateau. Journal of Geographical Sciences, 19(3): 331-339.

Yamada S, 1999. The role of soil creep and slope failure in the landscape evolution of a head water basin: Field measurements in a zero order basin of northern Japan. Geomorphology, 28(3/4): 329-344.

Yang Guifang, Zhang Xujiao, Tian Mingzhong et al., 2011. Alluvial terrace systems in Zhangjiajie of northwest Hunan, China: Implications for climatic change, tectonic uplift and geomorphic evolution. Quaternary International, 233(1): 27-39.

Zevenbergen L W, Thorne C R, 1987. Quantitative analysis of land surface topography. Earth Surface Processes and Landforms, 12(1): 47-56.

Zhang Liping, Ma Zhizheng, 1998. The research on the relation between gully density and cutting depth in different drainage landform evolution periods. Geographical Research, 17(3): 273-278. (in Chinese)

Zhou Qiming, Liu Xuejun, 2006a. Digital Terrain Analysis. Beijing: Science Press. (in Chinese)

Zhou Yi, Tang Guoan, Yang Xin et al., 2010. Positive and negative terrains on northern Shaanxi Loess Plateau. Journal of Geographical Sciences, 20(1): 64-76.

Zhou Zhengchao, Shangguan Zhouping, Zhao Duli, 2006b. Modeling vegetation coverage and soil erosion in the Loess Plateau Area of China. Ecological Modelling, 198(1/2): 263-268. 